\title{
36. GEOMAGNETIC PALEOINTENSITY MEASUREMENTS ON LEG 55 BASALTS
}

\author{
Masaru Kono and Toshiyuki Tosha, Geophysical Institute, University of Tokyo, Tokyo 113, Japan
}

\section{INTRODUCTION}

Although numerous rock magnetic and paleomagnetic studies have been carried out on dredged or drilled sea-floor basalts (Lowrie, 1977), studies of paleointensity have been relatively rare. Ozima et al. (1968) applied the Thellier method to basaltic rocks - dredged from the North Pacific and recovered from the experimental Mohole - having K-Ar ages between 3 and 92 m.y. Grommé et al. (1975) applied the Thellier method to dredged fragments of submarine pillow basalts 700,000 years old or younger. Carmichael (1977) used comparisons of decay modes of natural remanent magnetization (NRM) and thermoremanent magnetization (TRM) in thermal as well as alternating-field (AF) demagnetization on DSDP Leg 37 basalts (3 to 13 m.y. old). Dunlop and Hale (1977) also applied the Thellier method to Leg 37 basalts.

In these studies, the results are not very reliable because of changes in the magnetic properties of oceanic basalts when they are heated to produce TRM. In fact, Carmichael (1977) found that saturation remanence increased 2 to 5 times when samples were heated to about $600^{\circ} \mathrm{C}$. Such behavior is common in oceanic basalts. The most common ferromagnetic minerals in oceanic basalts are titanomaghemites, or titanomagnetites oxidized at low temperatures, which are metastable and decompose upon heating into Ti-poor titanomagnetite and Ti-rich hemoilmenite (Ozima and Ozima, 1971). Since titanomaghemites are secondary minerals formed by oxidation of titanomagnetites at low temperatures $\left(\lesssim 300^{\circ} \mathrm{C}\right)$, paleointensity results from samples containing them are not reliable even when the NRM-TRM plot is linear at lower temperatures (e.g., Ozima et al., 1968). There is no guarantee that the NRM is truly of TRM origin in such samples. Grommé et al. (1975) report that linear relations with different NRM-TRM gradients were obtained in paleointensity experiments on samples taken from a single pillow basalt which had varying degrees of low-temperature oxidation. The use of samples with low-oxidation-state titanomagnetites may circumvent these difficulties. Dunlop and Hale (1977), however, found that samples with a Curie point near $200^{\circ} \mathrm{C}$ are chemically stable when heated, but that they are magnetically soft and acquire viscous remanent magnetization (VRM) quite easily.

Thus far, application of paleointensity methods had not been very successful because of the difficulties inherent in ferromagnetic minerals of ocean-floor basalts, discussed earlier. In the Leg 55 basalts the situation was quite different. Though they were cored from submarine basement, all the evidence suggests that they erupted subaerially when the seamounts were above sea level, just as with the Hawaiian islands of today. Moreover, most of the ferromagnetic minerals in them are titanomagnetites oxidized at high temperatures, with Curie points in the range $550^{\circ}$ to $590^{\circ} \mathrm{C}$, and have not been affected by the later low-temperature oxidation (Kono, this volume). The Leg 55 basalts are characterized by high Curie point, large saturation remanence/saturation magnetization ratio $\left(\mathrm{J}_{\mathrm{r}} / \mathrm{J}_{\mathrm{s}}\right)$, and high magnetic stability, indicated by large median demagnetizing field (MDF) and small change of NRM direction in AF demagnetization (Kono, this volume; Kono, this volume). These observations suggest that Leg 55 basalts may be suitable for paleointensity experiments. We tried to obtain paleointensities from these samples using two different methods.

\section{EXPERIMENTAL PROCEDURES}

\section{Selection of Samples}

The seamounts drilled on Leg 55 were dated by Dalrymple et al. (this volume) at 55.2 m.y. (Ōjin), 56.2 m.y. (Nintoku), and 64.7 m.y. (Suiko), respectively. Samples used for paleointensity experiments were minicores $2.5 \mathrm{~cm}$ in diameter and $2.3 \mathrm{~cm}$ long. Samples for Shaw's method were selected considering AF demagnetization behavior; samples with moderate to high MDF ( $~ Z 300 \mathrm{Oe})$ and small directional change in $\mathrm{AF}$ demagnetization were chosen. The experiment is still in progress, so the results reported here deal principally with two holes, 430A ( $\overline{\mathrm{O} j i n}$ ) and 432A (Nintoku).

Samples for the Thellier method were selected mostly on the basis of the shapes of $\mathrm{J}_{\mathrm{s}}-\mathrm{T}$ curves in thermomagnetic analyses (Kono, this volume) and, to a lesser degree, according to the stability in AF demagnetization. Samples with high Curie points $\left(>550^{\circ} \mathrm{C}\right)$ and reversible $\mathrm{J}_{\mathrm{s}}-\mathrm{T}$ curves were preferred.

As shown by Kono (this volume), the basalts from Site 433 (Suiko) offer a good record of secular variation when the rocks erupted about 65 m.y. ago. We tried to determine paleointensities corresponding to various values of inclination, to see the secular variation in intensity and its relation to the directional change of the geomagnetic field. Table 1 gives a summary of samples used in paleointensity experiments.

\section{Shaw's Method}

Sixteen samples from seven flow units were studied in experiments employing Shaw's method. The experimental procedure was similar to that of the original investigator (Shaw, 1974), and can be divided into the following steps: (1) The NRM was demagnetized in an alternating field, and the peak field was increased in steps of 50 Oe between 0 and $200 \mathrm{Oe}$ and steps of $100 \mathrm{Oe}$ 
TABLE 1

List of Samples Used in Paleointensity Experiments

\begin{tabular}{|c|c|c|c|c|c|}
\hline \multirow{2}{*}{$\begin{array}{c}\text { Hole } \\
\text { (Seamount) }\end{array}$} & \multirow{2}{*}{$\begin{array}{l}\text { Flow } \\
\text { Unit }\end{array}$} & \multirow{2}{*}{$\begin{array}{l}\text { Sub-Bottom } \\
\text { Depth (m) }\end{array}$} & \multirow{2}{*}{$\begin{array}{c}\text { Inclination } \\
\left({ }^{\circ}\right)\end{array}$} & \multicolumn{2}{|c|}{ Sample (Interval in $\mathrm{cm}$ ) } \\
\hline & & & & Thellier Method & Shaw's Method \\
\hline \multirow{3}{*}{$\begin{array}{l}430 \mathrm{~A} \\
(\overline{\mathrm{O}} \text { jin })\end{array}$} & 1 & $52.0-71.4$ & -18.4 & $5-2,30-32$ & $4-2,88-90 ; 5-2,21-23$ \\
\hline & 2 & 71.476 .9 & -17.4 & $5-5,44-46$ & $5-4,132-134 ; 5-5,76-78$ \\
\hline & 3 & $76.9-79.2$ & -22.4 & $6-2,54-56$ & $6-2,74-76 ; 6-3,55-57$ \\
\hline \multirow{3}{*}{$\begin{array}{l}432 \mathrm{~A} \\
\text { (Nintoku) }\end{array}$} & 1 & $42.0-42.8$ & -65.2 & & $2-1,115-117 ; 2-1,133-135$ \\
\hline & 2 & $42.8-44.6$ & -66.4 & $2-2,72-74$ & $2-2,66-68 ; 2-3,2-4$ \\
\hline & 3 & $55.0-73.8$ & -28.6 & $4-1,64-66$ & $\begin{array}{l}3-3,92-94 ; 4-1,69-71 \\
4-2,41-43\end{array}$ \\
\hline & 4 & $202.7-210.0$ & -43.0 & $10-3,145-147$ & $10-2,21-23$ \\
\hline \multirow{8}{*}{ (Suiko) } & 8 & $217.9-223.9$ & -53.0 & $11-1,139-141$ & $11-4,58-60$ \\
\hline & & & & $11-5,36-38$ & \\
\hline & $11 \mathrm{~A}$ & $233.0-235.0$ & -33.4 & $14-2,37-39$ & \\
\hline & 20 & $317.6-319.6$ & -40.1 & $25-2,27-29$ & \\
\hline & 25 & $343.1-350.3$ & -49.6 & $35-6,48-50$ & \\
\hline & 48 & $450.3-458.5$ & -44.1 & $39-6,78-80$ & \\
\hline & 52 & $476.6-480.0$ & -13.6 & $42-1,68-70$ & \\
\hline & 64 & $529.7-539.5$ & -68.1 & $48-3,30-32$ & \\
\hline
\end{tabular}

${ }^{\mathrm{a}}$ Flow mean inclination from Kono (this volume).

between 200 and 1000 Oe; the remanence was measured after each demagnetization step. Samples were demagnetized using a Schonstedt AC demagnetizer, and the remanence was measured on a Digico spinner magnetometer. (2) An anhysteretic remanent magnetization (ARM) was induced in the sample using a direct field of $1.74 \mathrm{Oe}(0.87 \mathrm{Oe}$ for some samples) and a peak AF of 1000 Oe. This ARM (called ARM 1) was progressively demagnetized in an AF and measured as in (1). (3) TRM was then produced in the sample by heating it in air to $590^{\circ} \mathrm{C}$ for 18 minutes and cooling in a constant magnetic field of 0.44 Oe. The TRM was demagnetized and measured as in (1). (4) The sample was then given an ARM (called ARM 2) with the same direct and alternating fields as in (2). The ARM 2 was demagnetized and measured as in (1).

Results from these experiments were plotted in two diagrams, an ARM 1-ARM 2 plot and an NRM-TRM plot, and divided into classes according to the relations indicated in the two diagrams. The criteria for classification are as follows (Kono, 1978):

1) ARM 1-ARM 2 relation is linear, with a gradient of 1 .

2) ARM 1-ARM 2 relation is linear but the gradient is not 1 .

3) ARM 1-ARM 2 relation is non-linear. and

a) NRM-TRM relation is linear and the straight line goes through the origin.

b) NRM-TRM relation is linear, but the straight line does not go through the origin.

c) NRM-TRM relation is non-linear.

The experimental results were classified into the nine possible combinations of the above, e.g., class $1 \mathrm{a}, 2 \mathrm{~b}$, etc. Shaw (1974) accepted only results of class 1a, but Kono (1978) found that most of the results in classes $1 b$, $2 \mathrm{a}, 2 \mathrm{~b}$ give good paleointensities when appropriate slope correction is applied. In this study we considered results in classes 1 and 2, but with ARM 1-ARM 2 gradients between 0.5 and 2 , and discarded others as failures, even if linear relations occurred both in ARM 1-ARM 2 and NRM-TRM diagrams.

\section{Thellier Method}

Thirty-two samples from different flow units were subjected to the Thellier method (Thellier and Thellier, 1959). The experimental procedure was similar to that of Coe (1967). Samples were heated twice to the same temperature and cooled to room temperature, once in a non-magnetic field and once in a constant field of 0.5 Oe. Heating was carried out in air by an electric furnace placed in a Permalloy shield. The non-magnetic field in this case was not very good; a residual field of about 100 gammas $(0.001 \mathrm{Oe})$ was present in the sample space. Though the furnace had some temperature gradient in it, the samples were placed at the same place in the furnace for all the heatings. The reproducibility of temperatures in paired heating is estimated to have been within $5^{\circ} \mathrm{C}$. The remanence at room temperature after each heating was measured using a Schonstedt spinner magnetometer.

\section{RESULTS AND DISCUSSION}

\section{Shaw's Method}

Successful results from Shaw's method are summarized in Table 2 and illustrated in Figure 1. Five out of 16 samples gave satisfactory results. An experiment was considered successful if it yielded a class 1a result or if the result was class $1 b, 2 a$, or $2 b$ and six or more points of higher coercivity belonged to linear portions of the ARM 1-ARM 2 and NRM-TRM plots. The paleointensity was calculated from the slopes of the linear relations in the ARM 1-ARM 2 and NRM-TRM diagrams as

$$
F=0.44 \times \frac{\text { NRM-TRM slope }}{\text { ARM 1-ARM } 2 \text { slope }}
$$

Peculiarly, the ARM in all samples was demagnetized almost completely at $800 \mathrm{Oe}$, instead of the 1000 Oe at which the ARM was originally induced. Since the NRM and TRM show smooth decreases of intensity between 800 and 1000 Oe in AF demagnetization, most samples certainly contain ferromagnetic minerals with coercivities between 800 and 1000 Oe. Some defect in the demagnetizer probably caused the absence of a high coercivity portion of the ARM.

The results here are not excellent (no results can be classified as 1a), and multiple results were not obtained for most of the lava flows, so the results are not very reliable. Apparently the maximum field of 1000 Oe was not enough to obtain reliable paleointensity results from some samples. We are now trying to apply Shaw's method with higher demagnetizing field and many more samples.

\section{Thellier Method}

Eight out of 32 samples gave paleointensity estimates in the experiments using the Thellier method. These results are summarized in Table 3 and Figure 2. The criteria of success in this study were similar to those 
TABLE 2

Successful Results of Experiments Using Shaw's Method

\begin{tabular}{|c|c|c|c|c|c|c|c|c|c|c|c|}
\hline \multirow{2}{*}{$\begin{array}{c}\text { Sample } \\
\text { (Interval in } \mathrm{cm} \text { ) }\end{array}$} & \multirow{2}{*}{$\begin{array}{l}\text { Flow } \\
\text { Unit }\end{array}$} & \multirow{2}{*}{$\begin{array}{l}\text { MDF } \\
(\mathrm{Oe})\end{array}$} & \multirow{2}{*}{$\begin{array}{l}\mathrm{H}_{1} \\
(\mathrm{Oe})\end{array}$} & \multirow{2}{*}{$\begin{array}{c}\mathrm{H}_{2} \\
(\mathrm{Oe})\end{array}$} & \multirow[b]{2}{*}{$N$} & \multicolumn{2}{|c|}{ ARM 1-ARM 2} & \multicolumn{2}{|c|}{ NRM-TRM } & \multirow{2}{*}{$\begin{array}{l}F \pm \text { s.e. } \\
(\mathrm{Oe})\end{array}$} & \multirow[b]{2}{*}{ Class } \\
\hline & & & & & & Gradient & s.e. & Gradient & s.e. & & \\
\hline $430 \mathrm{~A}-5-5,76-78$ & 2 & 312 & 500 & 1000 & 6 & 0.53 & 0.01 & 0.97 & 0.04 & $0.81 \pm 0.05$ & $2 \mathrm{~b}$ \\
\hline $432 \mathrm{~A}-2-1,115-117$ & 1 & 329 & 200 & 1000 & 9 & 0.91 & 0.00 & 0.38 & 0.01 & $0.19 \pm 0.01$ & $2 \mathrm{a}$ \\
\hline $432 A-2-2,66-68$ & 2 & 410 & 600 & 1000 & 6 & 1.08 & 0.02 & 3.00 & 0.07 & $1.23 \pm 0.05$ & $2 \mathrm{~b}$ \\
\hline $432 \mathrm{~A}-4-2,41-43$ & 3 & 258 & 500 & 1000 & 6 & 0.51 & 0.03 & 0.41 & 0.00 & $0.36 \pm 0.02$ & $2 b$ \\
\hline $433 C-11-4,58-60$ & 8 & 531 & 500 & 1000 & 6 & 0.96 & 0.04 & 0.30 & 0.00 & $0.14 \pm 0.01$ & $2 \mathrm{~b}$ \\
\hline
\end{tabular}

Note: MDF is flow average median demagnetizing field. $\mathrm{H}_{1}$ and $\mathrm{H}_{2}$ indicate coercivity interval in which both ARM 1ARM 2 and NRM-TRM relations are linear; $N$ is the number of data points in this interval. $F$ is paleointensity. Class is explained in text.
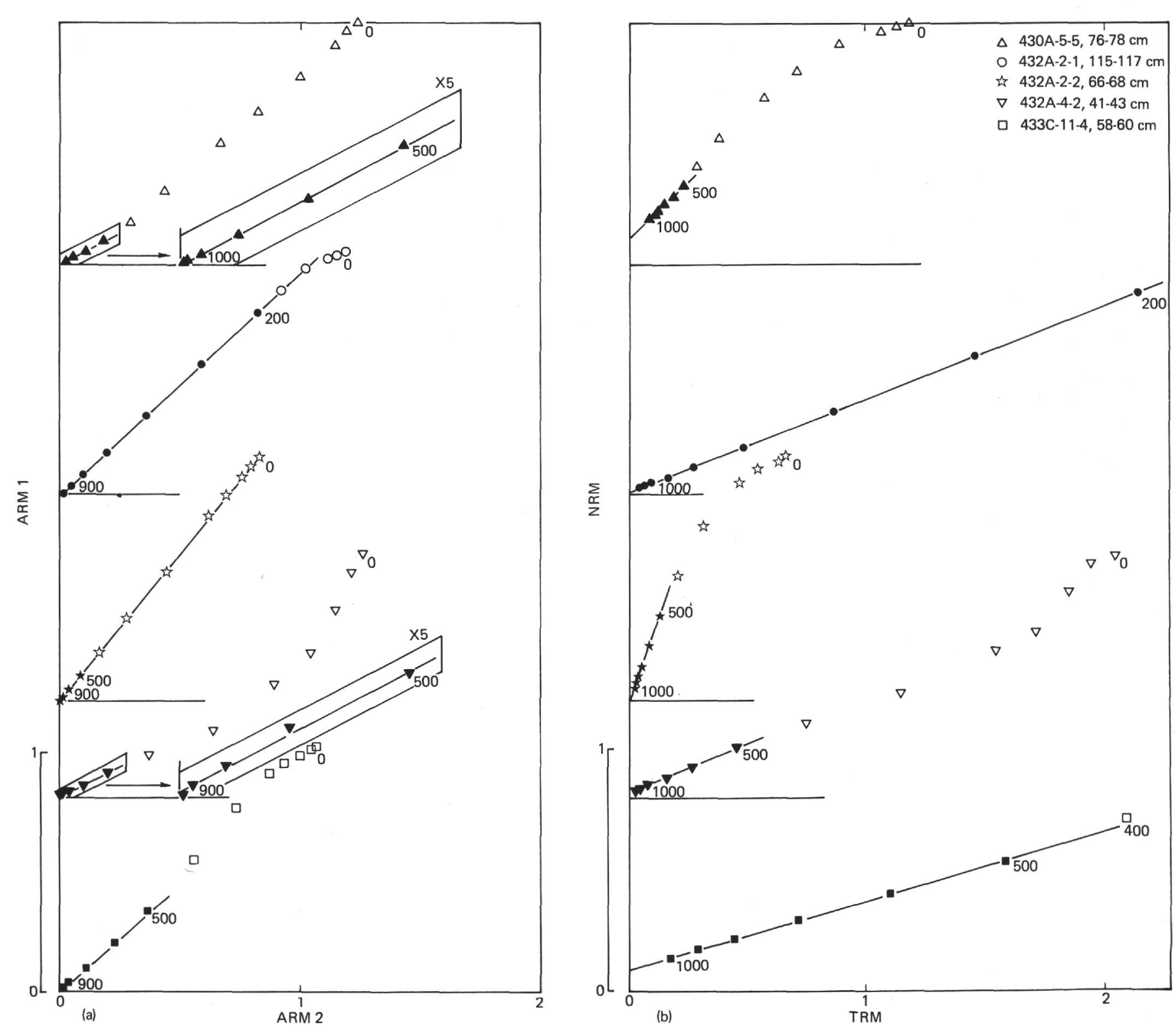

Figure 1. Successful results of paleointensity determination by Shaw's method. (a) Comparison of ARM 1 and ARM 2 at successively higher AF demagnetization stages. (b) Comparison of NRM and TRM at various demagnetization stages. Origins for individual data are shown by horizontal and vertical lines. The units of remanences are the total ARM 1 (a) or total NRM (b) of individual samples. The solid symbols indicate demagnetizing stages belonging to linear portions in both diagrams, and open symbols are data excluded from regression analysis. Some of the AF steps are indicated by small numerals (unit: peak Oe). Some portions of diagrams are enlarged to show details. 
TABLE 3

Successful Results of Experiments Using Theillier's Method

\begin{tabular}{|c|c|c|c|c|c|c|c|c|c|}
\hline $\begin{array}{c}\text { Sample } \\
\text { (Interval in } \mathrm{cm} \text { ) }\end{array}$ & $\begin{array}{l}\text { Flow } \\
\text { Unit }\end{array}$ & $\begin{array}{l}\mathrm{T}_{\mathrm{C}} \\
\left({ }^{\circ} \mathrm{C}\right)\end{array}$ & $\begin{array}{l}\mathrm{T}_{1} \\
\left({ }^{\circ} \mathrm{C}\right)\end{array}$ & $\begin{array}{l}\mathrm{T}_{2} \\
\left({ }^{\circ} \mathrm{C}\right)\end{array}$ & $N$ & $-r$ & $-b$ & $s_{b}$ & $\begin{array}{c}F \pm \text { s.e. } \\
(\mathrm{Oe})\end{array}$ \\
\hline \multicolumn{10}{|l|}{ Hole 430A } \\
\hline $5-5,44-46$ & 2 & 575 & 120 & 500 & 8 & 0.987 & 2.14 & 0.14 & $1.07 \pm 0.07$ \\
\hline $6-2,54-56$ & 3 & 582 & 200 & 600 & 6 & 0.996 & 1.61 & 0.07 & $0.81 \pm 0.04$ \\
\hline \multicolumn{10}{|l|}{ Hole 433C } \\
\hline $14-2,37-39$ & $11 \mathrm{~A}$ & 574 & 120 & 460 & 7 & 0.981 & 1.00 & 0.09 & $0.50 \pm 0.05$ \\
\hline $25-2,27-29$ & 20 & 570 & 280 & 620 & 9 & 0.991 & 0.66 & 0.05 & $0.33 \pm 0.02$ \\
\hline $35-6,48-50$ & 35 & 557 & 0 & 460 & 8 & 0.988 & 1.01 & 0.07 & $0.51 \pm 0.03$ \\
\hline $39-6,78-80$ & 48 & 573 & 0 & 420 & 7 & 0.997 & 0.77 & 0.03 & $0.39 \pm 0.01$ \\
\hline $42-1,68-70$ & 52 & 584 & 120 & 500 & 8 & 0.988 & 2.66 & 0.17 & $1.33 \pm 0.09$ \\
\hline $48-3,30-32$ & 64 & 575 & 120 & 460 & 7 & 0.980 & 1.46 & 0.13 & $0.73 \pm 0.07$ \\
\hline
\end{tabular}

used by Kono (1974), namely, (1) six or more points in the linear portion and (2) a correlation coefficient of regression between NRM and TRM components equal to or greater than 0.98 .

In these experiments, the direction of the NRM component in most samples did not change much up to $500^{\circ} \mathrm{C}$ or more. But the NRM-TRM linear relation was observed only in a quarter of the samples. In the Thellier method, unlike Shaw's method, samples were heated and kept at the prescribed temperatures for about one hour. The abundance of unsuccessful results may have been caused by the prolonged heatings. Changes in magnetic properties caused oy heating are very common in volcanic rocks, and most of the high temperature points $\left(\geq 500^{\circ} \mathrm{C}\right)$ deviate from the straight lines in NRM-TRM diagrams, even in successful results (Figure 2). At the low temperature end, many of the results show that the points lie below the straight lines. This can be interpreted as a result of superposition of the VRM component in the present field direction, since all the Leg 55 samples are reversely magnetized. These deviations from the ideal straight lines at low and high temperatures are common in many paleointensity studies (e.g., Kono, 1978).

\section{Intensities in the Early Cenozoic}

Table 4 is a summary of successful paleointensity results from Leg 55 basalts. The virtual dipole moment (VDM) in this table is the magnitude of a hypothetical geocentric dipole which would produce the observed inclination $(I)$ and total force $(F)$ at the sampling site, and can be calculated from the formula

$$
\mathrm{VDM}=\frac{1}{2} F^{3}\left(1+3 \cos ^{2} I\right)^{1 / 2}
$$

where $r$ is the earth's radius and $I$ the flow mean inclination (Kono, this volume) rather than the inclination of the paleointensity sample. VDMs for the Leg 55 basalts range from $2.5 \times 10^{25} \mathrm{G} \mathrm{cm}^{3}$ to $33.6 \times 10^{25} \mathrm{G} \mathrm{cm}^{3}$, with a mean of $13.1 \times 10^{25} \mathrm{G} \mathrm{cm}^{3}$, which is much larger than the present value of $8.0 \times 10^{25} \mathrm{G} \mathrm{cm}^{3}$. The differences between sites (holes) cannot be made clear at this stage, since the number of successful results for each site is not large enough.

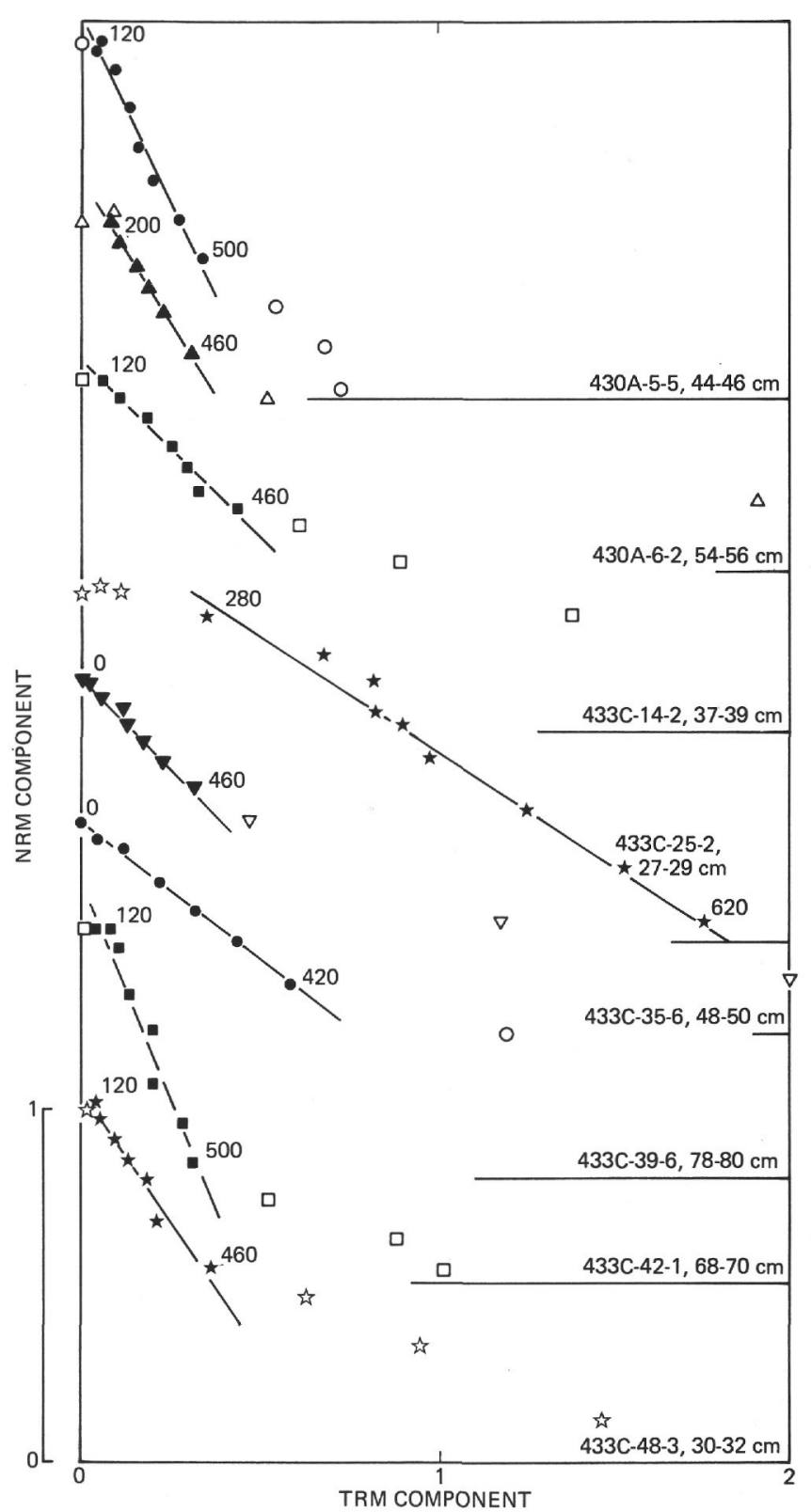

Figure 2. Successful results of paleointensity determination by the Thellier method. The ordinate and the abscissa are the NRM remaining at and the partial TRM acquired below the temperature of successive heatings. Some of the heating temperatures are indicated in the figure $\left({ }^{\circ} \mathrm{C}\right)$. Points expressed by open symbols are excluded from regression analysis because of some non-ideal behavior. The unit of remanence is the total NRM of each sample.

Paleointensities of the geomagnetic field at nearly the same time as these seamounts formed are only available from Deccan Trap basalts with K-Ar ages between 60 and $65 \mathrm{~m}, \mathrm{y}$. (Kono, 1974). For Deccan basalts, nine paleointensity estimates were obtained, with a mean VDM of $7.2 \pm 3.0$ (s.d.) $\times 10^{25} \mathrm{G} \mathrm{cm}^{3}$. The present VDM values are, on the whole, larger than the values obtained from Deccan basalts. In particular, many of 
TABLE 4

Summary of Paleointensity Results

\begin{tabular}{cccccc}
\hline Hole & $\begin{array}{c}\text { Flow } \\
\text { Unit }\end{array}$ & $\begin{array}{c}\text { Inclination } \\
\left({ }^{\circ} \mathrm{C}\right)\end{array}$ & $\begin{array}{c}F \\
(\mathrm{Oe})\end{array}$ & $\begin{array}{c}\text { VDM } \\
\left.\left(\times 10^{25} \mathrm{G} \mathrm{cm}\right)^{3}\right)\end{array}$ & Methoda \\
\hline $430 \mathrm{~A}$ & $2 \mathrm{~b}$ & -17.4 & 0.94 & 23.5 & $\mathrm{~T}, \mathrm{~S}$ \\
& 3 & -22.4 & 0.81 & 19.6 & $\mathrm{~T}$ \\
$432 \mathrm{~A}$ & 1 & -65.2 & 0.19 & 3.0 & $\mathrm{~S}$ \\
& 2 & -66.4 & 1.23 & 19.3 & $\mathrm{~S}$ \\
$433 \mathrm{C}$ & 3 & -28.6 & 0.36 & 8.4 & $\mathrm{~S}$ \\
& $11 \mathrm{~A}$ & -53.0 & 0.14 & 2.5 & $\mathrm{~S}$ \\
& 20 & -33.4 & 0.50 & 11.4 & $\mathrm{~T}$ \\
& 35 & -49.1 & 0.33 & 7.0 & $\mathrm{~T}$ \\
& 48 & -44.1 & 0.51 & 9.9 & $\mathrm{~T}$ \\
& 52 & -13.6 & 1.39 & 8.0 & $\mathrm{~T}$ \\
& 64 & -68.1 & 0.73 & 11.3 & $\mathrm{~T}$ \\
\hline
\end{tabular}

${ }^{\mathrm{a}} \mathrm{T}$ indicates the Theillier method. $\mathrm{S}$ is for Shaw's method.

${ }^{b}$ Mean of the two paleointensity estimates.

the flow units with inclinations much different from the mean inclination of the hole have unusually high VDM values. Because the number of flow units is not enough for Holes 430A and 432A, the mean inclinations in these holes have no physical meaning. In Hole 433C, however, the mean inclination $\left(-45.7^{\circ}\right)$ probably corresponds to the dipole field direction, because the secular variation is adequately sampled in this hole. Therefore, if a flow mean inclination in Hole $433 \mathrm{C}$ is quite different from the hole mean, it indicates either a time when non-dipole field was large at the sampling site or when the field was different from the dipole regime - i.e., geomagnetic reversal or excursion. A large deviation of field direction from the dipole direction may well be accompanied by a large change in the field strength. If the source of such non-dipole disturbance lies in the shallow layers of the earth's core, it would be plausible for large changes to be observed in both the direction and intensity of the magnetic field when such non-dipole source comes near to the observation point.

Alternatively, the large field intensity when the inclination is unusually small (Flow Units 2 and 3, Hole 430A; Flow Unit 52, Hole 433C) may correspond to the intensity maximum while the geomagnetic field was reversing its polarity. Such a phenomenon has already been reported by Shaw (1975). In any case, we have to have much more data before we can confidently draw conclusions about the intensity variation in the early Cenozoic. We shall postpone the full discussion of intensity data until we finish more extensive experiments.

\section{CONCLUSIONS}

Both the Thellier method and Shaw's method were applied to samples of Leg 55 basalts to determine intensities of the geomagnetic field in the early Cenozoic. The success rates in the experiments were 5/16 (Shaw's method) and 8/32 (the Thellier method). Internal consistency of data cannot be demonstrated, because only one paleointensity estimate is available for individual flow units, except Flow Unit 2 of Ōjin. Results from Shaw's method are not very good, in that some change occurred in ARM by heating and the ARMs lack the coercivity interval between 800 and 1000 Oe. For many samples, a demagnetizing field higher than 1000 Oe seems necessary to obtain reliable data. In successful results from the Thellier method, linearity of NRM and TRM components occurs approximately between $100^{\circ}$ and $500^{\circ} \mathrm{C}$. Deviation from the linear line at low temperatures is a result of a superposed VRM component in the present field direction. Deviation at high temperatures is probably caused by some change in chemistry or grain-size distribution of ferromagnetic minerals. This point is discussed in a separate paper (Kono, this volume).

The mean and standard deviation of VDMs calculated from the paleointensity results presented here are $13.1 \pm 9.2 \times 10^{25} \mathrm{~g} \mathrm{~cm}^{3}$. The mean is significantly larger and the range much wider than the corresponding values for the Deccan basalts of similar age $(7.2 \pm 3.0 \times$ $10^{25} \mathrm{G} \mathrm{cm}^{3}$ ). In Hole $433 \mathrm{C}$ (Suiko), flow units with inclinations much different from the hole mean inclination tend to give very large paleointensities. To determine whether this indicates the time when the non-dipole component was very large or the time of geomagnetic reversals or excursions is left for future studies.

\section{ACKNOWLEDGMENT}

We thank Yozo Hamano for useful discussions.

\section{REFERENCES}

Carmichael, C. M., 1977. Magnetization and paleomagnetic field intensity of selected samples from Sites 332, 334, and 335. In Aumento, F., Melson, W. G., et al., Initial Reports of the Deep Sea Drilling Project, v. 37: Washington (U. S. Government Printing Office), pp. 481-487.

Coe, R. S., 1967. Paleo-intensities of the earth's magnetic field determined from Tertiary and Quaternary rocks, $J$. Geophys. Res., v. 72, pp. 3247-3269.

Dunlop, D. J. and Hale, C. J., 1977. Magnetic properties of Leg 37 basalts and a determination of paleomagnetic field intensity. In Aumento, F., Melson, W. G., et al., Initial Reports of the Deep Sea Drilling Project, v. 37: Washington (U. S. Government Printing Office), pp. 457-463.

Grommé, C. S., Coe, R. S., Marshall, M., and Mankinen, E. A., 1975. Paleointensity measurements on submarine pillow basalts, IAGA Bull: Paris (IUGG Publ. Office), No. 36, p. 160.

Kono, M., 1974. Intensities of the earth's magnetic field about $60 \mathrm{~m} . \mathrm{y}$. ago determined from the Deccan Trap basalts, India, J. Geophys. Res., v. 79, pp. 1135-1141.

1978. Reliability of paleointensity methods using alternating field demagnetization and anhysteretic remanence, Geophys. J. Roy. Astron. Soc., v. 54, pp. 241-261.

Lowrie, W., 1977. Intensity and direction of magnetization in oceanic basalts, J. Geol. Soc. London, v. 133, pp. 61-82.

Ozima, M. and Ozima, M., 1971. Characteristic thermomagnetic curve in submarine basalts, J. Geophys. Res., v. 76, pp. 2051-2056.

Ozima, M., Ozima, M., and Kaneoka, I., 1968. Potassiumargon ages and magnetic properties of some dredged sub- 
marine basalts and their geophysical implications, $J$. Geophys. Res., v. 73, pp. 711-723.

Shaw, J., 1974. A new method of determining the magnitude of the palaeomagnetic field, application to five historic lavas and five archaeological samples, Geophys. J. Roy. Astron. Soc., v. 39, pp. 133-141.
1975. Strong geomagnetic fields during a single Icelandic polarity transition, Geophys. J. Roy. Astron. Soc., v. 40 , pp. $345-350$.

Thellier, E. and Thellier, O., 1959. Sur l'intensité du champ magnétique terrestre dans le passé historique et géologique, Ann. Géophys., v. 15, pp. 285-376. 